LETTER TO JMG

\title{
A novel locus for autosomal recessive form of hypotrichosis maps to chromosome 3q26.33-q27.3
}

\author{
M Aslam, M H Chahrour, A Razzaq, S Haque, K Yan, S M Leal, W Ahmad
}

J Med Genet 2004;41:849-852. doi: 10.1136/jimg.2004.019729

G enetic conditions affecting hair structure or the hair growth cycle may be isolated or they may occur as part of complex syndromes with associated abnormalities of other ectodermal appendages. Defective hair structure caused by mutations in key hair structural proteins can result in severe alopecia. The best characterised conditions at the molecular level in this category are monilethrix ${ }^{1}$ (MIM 158000) and Netherton syndrome ${ }^{3}$ (MIM 256500). Monilethrix is an autosomal dominant disorder in which alopecia is the presenting manifestation; however, the degree of alopecia is variable between patients and during different time periods for the same individual. Causative mutations have been identified in the keratin hair basic 6 gene (HB6, MIM 601928) and the keratin hair basic 1 gene (HBl, MIM $602153) .{ }^{4}$ Netherton syndrome is a rare autosomal recessive condition characterised by "bamboo hair" (trichorrhexis invaginata), congenital ichthyosiform erythroderma, and atopic diathesis. Serine protease inhibitor, Kazal-type 5 gene (SPINK5, MIM 605010), located on chromosome 5q31-q32, encodes a 15 domain serine protease inhibitor and is mutated in Netherton syndrome. ${ }^{3}$ Structural hair shaft defects are also a feature of Menkes kinky hair syndrome (MIM 309400). Menkes disease, ${ }^{5}$ with $\mathrm{X}$ linked inheritance, is caused by mutations in the gene encoding $\mathrm{Cu}^{2+}$ transporting ATPase, ATP7A (MIM 300011).

Isolated forms of alopecia include congenital atrichia and different forms of hypotrichosis, which may represent a dysregulation of the hair growth cycle and remodelling. ${ }^{7}$

Autosomal recessive congenital atrichia (MIM 203655) is the most extreme example of hair loss. In affected individuals with this form of alopecia, hair is typically absent from the scalp with shedding shortly after birth. Congenital atrichia has been linked to 8 p2 1 , where several mutations of the hairless gene (HR, MIM 602302) have been reported as the underlying cause of congenital atrichia. ${ }^{89}$

Marie Unna hereditary hypotrichosis (MUHH, MIM 146550) is an autosomal dominant disorder characterised by abnormal hair structure at birth, or soon after birth, with progressive hair loss leading to varying degrees of alopecia in adults. ${ }^{10}$ MUHH has been mapped to chromosome $8 \mathrm{p} 21$ in the vicinity of the hairless gene. ${ }^{10}$

Hypotrichosis simplex (HTS, MIM 605389) is an autosomal dominant disorder that can affect all bodily hair or can be limited to the scalp. Levy-Nissenbaum et $a l^{11}$ found nonsense mutations in corneodesmosin gene (CDSN, MIM 602593), located on chromosome 6p21.3, in three families with hypotrichosis simplex of the scalp (HTSS, MIM 146520).

In autosomal recessive localised hereditary hypotrichosis (LAH, MIM 607903), the affected individuals show hypotrichosis restricted to the scalp, chest, arms, and legs. Facial hair, including the eyebrows and beard, is less dense, and axillary, pubic hair and eyelashes are unaffected. LAH has been linked to chromosomal location $18 \mathrm{q} 21.1^{12}{ }^{13}$ which

\section{Key points}

- Human genome scan identified a novel hypotrichosis locus in a consanguineous Pakistani family segregating autosomal recessive hypotrichosis.

- The novel hereditary hypotrichosis locus, $\mathrm{AH}$, was mapped to chromosome 3q26.33-q27.3.

- A maximum multipoint LOD score of 6.0 was obtained at marker D3S3592.

- The region of homozygosity was flanked by markers D3S2314 and D3S1602.

- This genetic interval spans $7.1 \mathrm{cM}$, according to the deCode genetic map, and contains $3.9 \mathrm{Mb}$ on the sequence based physical map.

contains a cluster of desmoglein and desmocollin genes. Recently, mutations in the desmoglein 4 gene (DSG4, MIM 607892) have been implicated in LAH. ${ }^{12}$

We studied a highly consanguineous family with the autosomal recessive form of hereditary hypotrichosis. After exclusion of all the known loci, a genome scan was undertaken which led to the identification of a novel locus, $\mathrm{AH}$, for this form of hereditary hypotrichosis, mapped to chromosome 3q26.33-q27.3 and flanked by markers D3S2314 and D3S1602.

\section{METHODS}

\section{Family data}

Before the onset of the study, approval was obtained from the Quaid-I-Azam University institutional review board. A consanguineous family segregating an autosomal recessive form of hypotrichosis as a sole abnormality without associated ectodermal defects was studied. The pedigree (fig 1) provided convincing evidence of an autosomal recessive mode of inheritance, and consanguineous matings accounted for all the affected individuals being homozygous for the mutant allele. All patients showed typical features of hereditary hypotrichosis. At birth, sparse hair was present on the scalp but did not regrow after ritual shaving, which is usually performed one week after birth. The affected individuals are nearly devoid of normal eyebrows, eyelashes, axillary hair, and body hair (fig 2). Affected male individuals of the family have normal beard hair; however, hair is absent on their legs and arms. Teeth and nails are normal in all affected individuals.

Abbreviations: LAH, localised autosomal recessive hypotrichosis; STR, short tandem repeat 


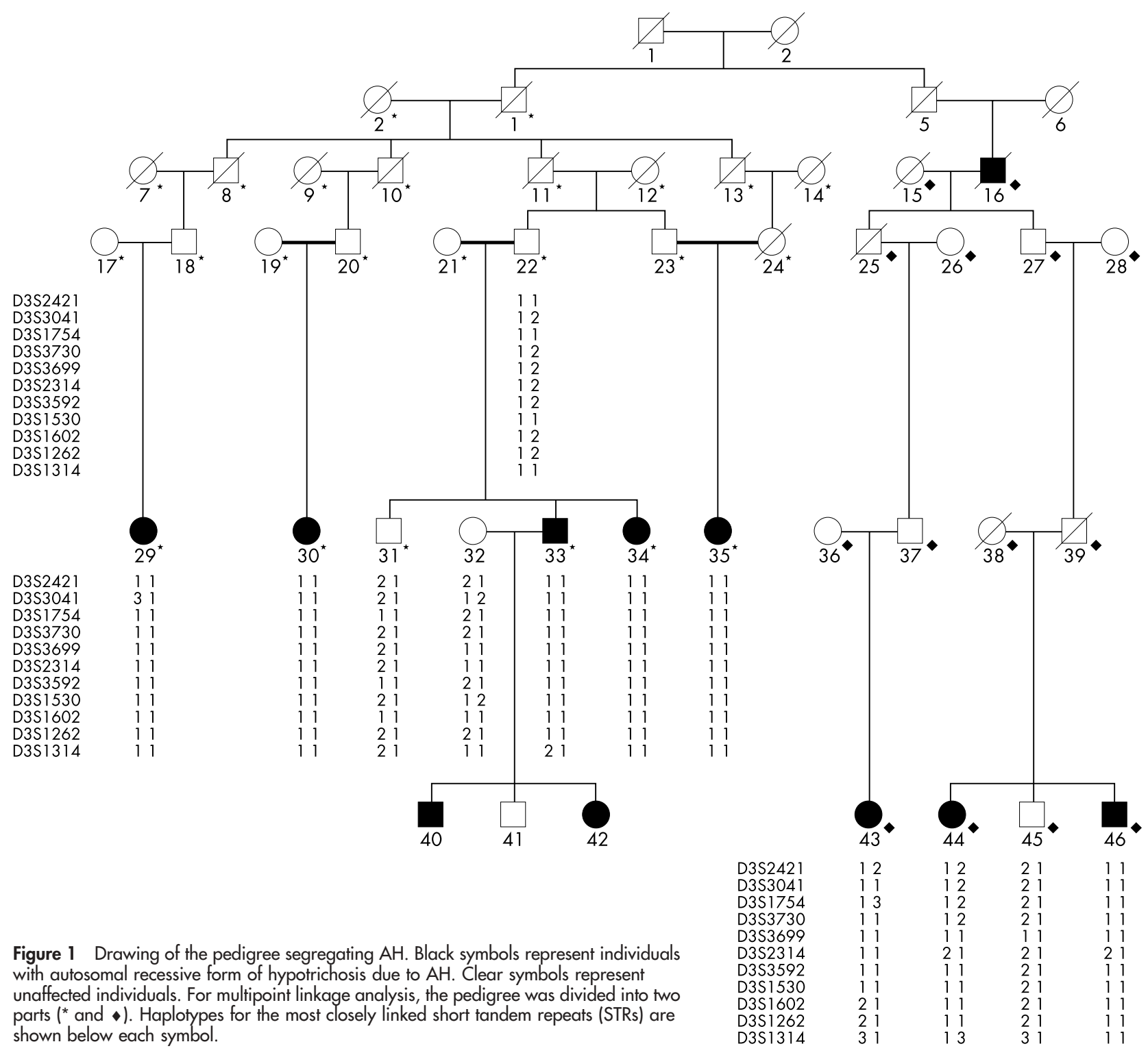

\section{Extraction of genomic DNA and PCR}

Venous blood samples were obtained from 12 family members, including eight affected individuals. Genomic DNA was extracted from whole blood following a standard protocol, quantified by spectrophotometric readings at optical density 260 and diluted to $40 \mathrm{ng} / \mu \mathrm{l}$ for polymerase chain reaction (PCR). PCR amplification of microsatellite markers was carried out according to standard procedure in a total volume of $25 \mu \mathrm{l}$, containing $40 \mathrm{ng}$ genomic DNA, $20 \mathrm{pmol}$ of each primer, $200 \mu \mathrm{M}$ of each dNTP, and $1 \times$ PCR buffer (MBIFermentas, Newcastle upon Tyne, UK).

PCR was carried out for 35 cycles, with the following thermal cycling conditions: $95^{\circ} \mathrm{C}$ for one minute, $57^{\circ} \mathrm{C}$ for one minute, and $72^{\circ} \mathrm{C}$ for one minute, followed by a final extension at $72^{\circ} \mathrm{C}$ for seven minutes in a thermal cycler (Perkin Elmer, Norwalk, Connecticut, USA). PCR products were resolved on $8 \%$ non-denaturing polyacrylamide gel, along with the appropriate allelic ladder, and genotypes were assigned by visual inspection.

The family was first tested for linkage by using microsatellite markers tightly linked to 14 loci associated with other forms of hair loss and ectodermal dysplasia. These included: type II keratin (KRT1) genes at 12q13.13 (D12S297, D12S368, D12S90); keratin hard type l (KRTHAl) genes at 17q21.2 (D17S1299, D17S800, D17S930, D17S934, D17S791, D17S797); desmoglein (DSG) and desmocollin (DSC) genes at 18q12.1 (Dl8S1107, D18S478, Dl8S847, D18S36, D18S536, D18S384); human hairless gene (HR) at 8p21.3 (D8S298, D8S1786, D8S1048); envoplakin (EVPL) at 17q25.1 (D17S1807, D17S1301, D17S785, D17S801, D17S784); loricrin (LOR) at lq21.3 (D1S534, DiS442, D1S498, D1S305); plakophilin 1 (PKPl) at lq32.1 (DiS1660, D1S1726, D1S2622, D1S373, D1S2655, D1S2686); ED2 gene gap junction protein $\beta-6$ (GJB6) at 13q12.11 (D13S1316, D13S175, D13S633, D13S250, D13S787); ED3 gene ectodysplasinl anhidrotic receptor (EDAR) at 2q12.3 (D2S1343, D2S2954, D2S340, D2S1889, D2S1893, D2S1891); ED4 gene poliovirus receptor-like 1 (PVRLl) at 1lq23.3 (Dl1S1885, Dl1S4171, D11S4129, Dl1S924, D11S1299); transglutaminase I (TGM1) at 14q11.2 (D14S50, D14S264, Di4S275, D14S1040); transglutaminase II (TGM2) at 20q11.23 (D20S909, D20S865, D20S834, D20S881, D20S478, D20S107); transglutaminase III (TGM3) at 20p13 (D20S906, D20S179, D20S113, D20S181, D20S193, 


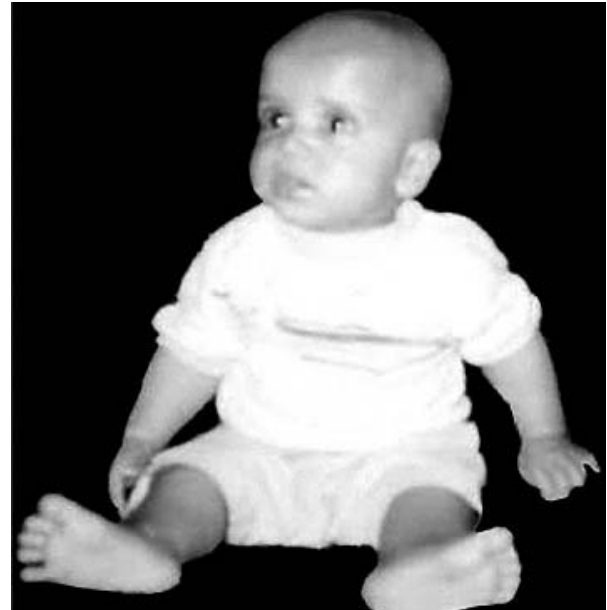

Figure 2 Clinical presentation of the AH phenotype. Note the complete absence of hair on the scalp. Reproduced with permission.

D20S473); and corneodesmosin (CDSN) at 6p21.33 (D6S273, D6S1615, D6S2414, D6S439, D6S2427). After known loci were excluded, a genome scan was conducted using highly informative polymorphic microsatellite markers from Linkage Mapping Set 10 (Invitrogen Co, San Diego, California, USA).

\section{Linkage analysis}

Two-point linkage analysis was carried out using the MLINK program of the FASTLINK computer package. ${ }^{14}$ Multipoint linkage analysis was undertaken using ALLEGRO, ${ }^{15}$ with the pedigree divided into two parts (fig l) owing to the large number of non-founders (the Lander-Green algorithm, ${ }^{16}$ which is implemented in ALLEGRO, ${ }^{15}$ can only handle small to medium sized pedigrees with a limited number of nonfounders). Multipoint LOD scores were calculated for each part and then summed. Haplotypes were constructed using SIMWALK2. ${ }^{17}{ }^{18}$ The order of the markers and their map distances were derived from the deCode genetic map. ${ }^{19}$ For the analysis, an autosomal recessive mode of inheritance with complete penetrance and a disease allele frequency of 0.001 were used. Equal allele frequencies were employed for the fine mapping markers, and because incorrect allele frequencies can lead to false positive results ${ }^{20}$ a sensitivity analysis was carried out. Multipoint linkage analysis was done by varying the allele frequency for the allele segregating with the disease allele from 0.2 to 0.7 for the fine mapping markers.

\section{RESULTS}

Exclusion of known loci and initial mapping

Haplotype analysis was undertaken for the markers linked to 14 known hair loss and ectodermal dysplasia loci (data not shown). Examination of the haplotypes did not reveal any regions of homozygosity within affected individuals.

After the known genes were excluded, a genome scan was carried out using the DNA samples of four affected individuals $(30,33,34$, and 35$)$. In the course of screening 345 markers, three markers from the deCode genetic map ${ }^{19}$ D1S2682 (274.3 cM at 1q44), D6S1006 (30.2 cM at 6p22.3), and D3S1262 (194.3 cM at 3q27.2)—were found to be homozygous in all four affected subjects. Upon testing the rest of the family members, linkage to two of these regions was excluded. All affected individuals were found to be homozygous at marker D3S1530, located at $191.8 \mathrm{cM}$ on chromosome 3, according to the deCode genetic map. ${ }^{19}$ Unaffected subjects were heterozygous at this marker, except for unaffected individual 22, who was homozygous.

\section{Refinement of linkage interval}

For fine mapping, 14 additional markers were selected from the deCode genetic map ${ }^{19} ; 10$ of these (D3S2421, D3S3041, D3S1754, D3S3730, D3S3699, D3S2314, D3S1618, D3S1571, D3S3583, and D3S3592) were proximal to marker D3S1530 and four were distal (D3S1617, D3S1602, D3S1262, and D3S1314). After genotyping all the family members with these markers, the data were analysed using two point and multipoint linkage analysis. Four of these markers (D3S1618, D3S1571, D3S3583, and D3S1617) were uninformative in this family and were not included in the analysis.

Table 1 summarises the two point LOD scores obtained for a total of 11 markers. The maximum two point LOD score of $2.4(\theta=0)$ was obtained at marker D3S1262. The maximum multipoint LOD score was obtained at marker D3S3592 $\left(Z_{\max }=6.0\right)$. When the allele frequency for the allele segregating with the disease allele was varied from 0.4 to 0.7 , the maximum multipoint LOD score remained at marker D3S3592, and varied from 6.2 to 4.2 , respectively. At allele frequencies of 0.2 and 0.3 , the maximum multipoint LOD score occurred at marker D3S1530, with values of 6.3 and 6.2. The three unit support interval is flanked by markers D3S3730 (184.1 cM) and D3S1314 (204.5 cM). It defines a genetic interval of $20.3 \mathrm{cM}$ on the deCode genetic map ${ }^{19}$ and contains $11.5 \mathrm{Mb}$ according to the sequence based physical map. ${ }^{21}$ The region of homozygosity further refined the linkage interval to $7.1 \mathrm{cM}$, according to the deCode genetic map, ${ }^{19}$ flanked by markers D3S2314 (186.6 cM) and D3S1602 (193.7 cM). This region contains $3.9 \mathrm{Mb}$ according to the sequence based physical map. ${ }^{21}$

Table 1 Two point LOD score results between the AH locus and chromosome 3 markers

\begin{tabular}{|c|c|c|c|c|c|c|c|c|c|c|c|}
\hline \multirow[b]{2}{*}{ Marker } & \multirow{2}{*}{$\begin{array}{l}\text { Decode map } \\
\text { position* }\end{array}$} & \multirow{2}{*}{$\begin{array}{l}\text { Physical map } \\
\text { position } †\end{array}$} & \multicolumn{9}{|c|}{ LOD score at recombination fraction $\theta=$} \\
\hline & & & 0.0 & 0.01 & 0.02 & 0.03 & 0.04 & 0.05 & 0.1 & 0.2 & 0.3 \\
\hline D3S2421 & 180.68 & 176395051 & $-\infty$ & 0.11 & 0.36 & 0.48 & 0.55 & 0.59 & 0.64 & 0.47 & 0.26 \\
\hline D3S3041 & 181.90 & 177800980 & $-\infty$ & 1.38 & 1.59 & 1.69 & 1.73 & 1.74 & 1.63 & 1.17 & 0.67 \\
\hline D3S1754 & 183.65 & 178762481 & $-\infty$ & 0.47 & 0.70 & 0.82 & 0.88 & 0.91 & 0.90 & 0.64 & 0.36 \\
\hline D3S3730 & 184.15 & 179867514 & $-\infty$ & 0.79 & 1.02 & 1.12 & 1.18 & 1.21 & 1.17 & 0.85 & 0.50 \\
\hline D3S3699 & 184.93 & 180617958 & 2.21 & 2.15 & 2.08 & 2.02 & 1.96 & 1.90 & 1.60 & 1.05 & 0.58 \\
\hline D3S2314 & 186.58 & 183451291 & 1.99 & 1.93 & 1.87 & 1.81 & 1.75 & 1.69 & 1.42 & 0.92 & 0.51 \\
\hline D3S3592 & 190.89 & 185731335 & 2.19 & 2.13 & 2.08 & 2.02 & 1.96 & 1.90 & 1.62 & 1.07 & 0.59 \\
\hline D3S1530 & 191.78 & 186704472 & 2.29 & 2.23 & 2.16 & 2.09 & 2.02 & 1.95 & 1.62 & 1.02 & 0.53 \\
\hline D3S 1602 & 193.69 & 187352606 & 1.92 & 1.87 & 1.82 & 1.77 & 1.72 & 1.67 & 1.41 & 0.93 & 0.51 \\
\hline D3S1262 & 194.33 & 187544392 & 2.44 & 2.37 & 2.30 & 2.23 & 2.16 & 2.09 & 1.76 & 1.15 & 0.62 \\
\hline D3S1314 & 204.48 & 191412788 & $-\infty$ & -1.00 & -0.46 & -0.18 & 0.01 & 0.13 & 0.41 & 0.42 & 0.27 \\
\hline
\end{tabular}

Markers in bold flank the haplotype.

*Sex averaged kosambi cM map distance from the deCode genetic map. ${ }^{18}$

†Sequence based physical map distance in bases according to the Human Genome Project. ${ }^{20}$ 


\section{DISCUSSION}

Among the isolated forms of hereditary alopecia, linkage has been established in diseases like monilethrix, Netherton syndrome, atrichia, hypotrichosis simplex, Marie Unna hypotrichosis, and localised autosomal recessive hypotrichosis. Except in the case of Marie Unna hypotrichosis, causative genes have been identified for all these disorders. These genes encode structural molecules, transcription factors, or morphogenetic factors of hair growth.

In the present study, a novel autosomal recessive hereditary hypotrichosis locus, $\mathrm{AH}$, was mapped to chromosome 3q26.33-q27.3. Significant evidence of linkage to this chromosomal region was found, with a maximum multipoint LOD score of 6.0 at marker D3S3592. The type of hereditary hypotrichosis observed in the affected individuals in this family is distinguished from atrichia by the presence of normal beard hair in affected male individuals, which is not observed in atrichia. However, the clinical manifestations of the affected individuals in this family closely resemble those reported for LAH. Affected individuals from both LAH and $\mathrm{AH}$ families have normal beard hair (in males), and sparse to absent eyebrows, eyelashes, and body hair. Despite clinical similarities, there was no evidence for linkage to the LAH region on chromosome $18 \mathrm{q} 21.1$ in this family.

According to the sequenced based physical map, ${ }^{21}$ the linkage interval on chromosome 3q26.33-q27.3 contains $3.9 \mathrm{Mb}$. Through a database search, we identified several genes mapping between markers D3S2314 and D3S1602, none of which, however, appears to be a plausible candidate for the AH locus. Among the several genes located in this region are the chloride channel 2 gene (CLCN2) (MIM 600570) associated with idiopathic generalised epilepsies; chordin (CHRD) (MIM 603475), a key developmental protein that dorsalises early vertebrate embryonic tissues; and the ubiquitously expressed ephrin receptor (EPHB3) (MIM 601839) which induces cell-cell adhesion and aggregation.

Hair growth occurs in unsynchronised cycles consisting of three phases: anagen (growth phase), catagen (shortening phase), and telogen (resting phase). The molecular mechanisms underlying hair follicle development are the subject of much current interest. A long list of cytokines and growth factors-including members of the epidermal, fibroblast, and transforming growth factor families-has been implicated in the hair growth cycle. Potter et al ${ }^{22}$ have shown that the hairless gene (HR), the causative gene for atrichia, is a component of the co-repressor machinery that may be active in the genetic pathway controlling postnatal cycling of the hair follicle. ${ }^{23}$ Recently, Kljuic et al ${ }^{12}$ have shown that desmoglein 4-a member of the cadherin family of proteins-plays a central role in keratinocyte cell adhesion in the hair follicle and in coordinating cellular dynamics in the lower hair follicle during the switch from proliferation to differentiation.

On the basis of clinical similarities observed between patients with $\mathrm{AH}$ and $\mathrm{LAH}$, it can be speculated that $\mathrm{AH}$ is caused by a change in cell adhesion molecules involved in hair follicle development. Identification of the gene implicated in the pathogenesis of AH will give valuable insight into the genetic mechanisms underlying different forms of baldness.

\section{ACKNOWLEDGEMENTS}

We wish to thank the family members for their cooperation. The work was funded by Higher Education Commission (HEC), Islamabad, Pakistan.

\section{Authors' affiliations \\ M Aslam, A Razzaq, S Haque, W Ahmad, Department of Biological Sciences, Quaid-I-Azam University, Islamabad, Pakistan}

M H Chahrour, K Yan, S M Leal, Department of Molecular and Human Genetics, Baylor College of Medicine, Houston, Texas, USA

Conflicts of interest: none declared.

Correspondence to: Dr Wasim Ahmad, Department of Biological Sciences, Quaid-I-Azam University Islamabad, Pakistan; wahmad@ qau.edu.pk

\section{REFERENCES}

1 Irvine AD, Christiano AM. Hair on a gene string: recent advances in understanding the molecular genetics of hair loss. Clin Exp Dermatol $2001 ; 26: 59-71$.

2 Magert HJ, Standker L, Kreutzmann P, Zucht HD, Reinecke M, Sommerhoff CP, Fritz H, Forssmann WG. LEKTI, a novel 15-domain type of human serine proteinase inhibitor. J Biol Chem 1999;274:21499-502.

3 Chavanas S, Garner C, Bodemer C, Ali M, Teillac DH, Wilkinson J, Bonafe JL, Paradisi M, Kelsell DP, Ansai S, Mitsuhashi Y, Larregue M, Leigh IM, Harper Jl, Taieb A, Prost Y, Cardon LR, Hovnanian A. Localization of the Netherton syndrome gene to chromosome $5 \mathrm{q} 32$, by linkage analysis and homozygosity mapping. Am J Hum Genet 2000;66:914-21.

4 Winter H, Rogers MA, Gebhardt M, Wollina U, Boxall L, Chitayat D, BabulHirji R, Stevens HP, Zlotogorski A, Schweizer J. A new mutation in the type II hair cortex keratin $\mathrm{hHbl}$ involved in the inherited hair disorder monilethrix. Nat Genet 1997; 101:165-9.

5 Hart DB. Menkes' syndrome: an updated review. J Am Acad Dermatol 1983:9:145-52.

6 Vulpe C, Levinson B, Whitney S, Packman S, Gitschier J. Isolation of a candidate gene for Menkes disease and evidence that it encodes a coppertransporting ATPase. Nat Genet 1993;3:7-13.

7 Hardy MH. The secret life of the hair follicle. Trends Genet 1992;8:55-61.

8 Ahmad W, Faiyaz ul Haque M, Brancolini V, Tsou HC, ul Haque S, Lam H, Aita VM, Owen J, deBlaquiere M, Frank J, Cserhalmi-Friedman PB, Leask A, McGrath JA, Peacocke M, Ahmad M, Ott J, Christiano AM. Alopecia universalis associated with a mutation in the human hairless gene. Science 1998;279:720-4.

9 Cichon S, Anker M, Vogt IR, Rohleder H, Putzstuck M, Hillmer A, Farooq SA, Al-Dhafri KS, Ahmad M, Haque S, Rietschel M, Propping P, Kruse R, Nothen MM. Cloning, genomic organization, alternative transcripts and mutational analysis of the gene responsible for autosomal recessive universal congenital alopecia. Hum Mol Genet 1998;7:1671-9.

10 Van Steensel M, Smith FJ, Steijlen PM, Kluiit I, Stevens HP, Messenger A Kremer H, Dunnill MG, Kennedy C, Munro CS, Doherty VR, McGrath JA Covello SP, Coleman CM, Uitto J, McLean WH. The gene for hypotrichosis of Marie Unna maps between D8S258 and D8S298: exclusion of the hr gene by cDNA and genomic sequencing. Am J Hum Genet 1999;65:413-19.

11 Levy-Nissenbaum E, Betz RC, Frydman M, et al. Hypotrichosis simplex of the scalp is associated with nonsense mutations in CDSN encoding corneodesmosin. Nat Genet 2003;34:151-3.

12 Kljuic A, Bazzi H, Sundberg JP, Martinez-Mir A, O'Shaughnessy R, Mahoney MG, Levy M, Montagutelli X, Ahmad W, Aita VM, Gordon D, Uitto J, Whiting D, Ott J, Fischer S, Gilliam TC, Jahoda CA, Morris RJ, Panteleyev AA, Nguyen VT, Christiano AM. Desmoglein 4 in hair follicle differentiation and epidermal adhesion: evidence from inherited hypotrichosis and acquired pemphigus vulgaris. Cell 2003;113:249-60.

13 Rafique MA, Ansar M, Jamal SM, Malik S, Sohail M, Faiyaz-Ul-Haque M, Haque S, Leal SM, Ahmad W. A locus for hereditary hypotrichosis localized to human chromosome 18q21.1. Eur J Hum Genet 2003:11:623-8.

14 Cottingham R, Indury RM, Schaffer AA. Faster sequential genetic linkage computations. Am J Hum Genet 1993;53:252-63.

15 Gudbjartsson DF, Jonasson K, Frigge ML, Kong A, et al. Allegro, a new computer program for multipoint linkage analysis. Nat Genet 2002;25:12-13.

16 Lander ES, Green P. Construction of multilocus genetic linkage maps in humans. Proc Natl Acad Sci USA 1987;84:2363-7.

17 Weeks DE, Sobel E, O'Connell JR, Lange K. Computer programs for multilocus haplotyping of general pedigrees. Am J Hum Genet 1995;56:1506-7.

18 Sobel E, Lange K. Descent graphs in pedigree analysis: applications to haplotyping, location scores, and marker-sharing statistics. Am J Hum Genet 1996:58:1323-37.

19 Kong A, Gudbjartsson DF, Sainz J, Jonsdottir GM, Gudjonsson SA, Richardsson B, Sigurdardottir S, Barnard J, Hallbeck B, Masson G, Shlien A, Palsson ST, Frigge ML, Thorgeirsson TE, Gulcher JR, Stefansson K. A highresolution recombination map of the human genome. Nat Genet 2002;31:241-7.

20 Freimer NB, Sandkuijl LA, Blower SM. Incorrect specification of marker allele frequencies: effects on linkage analysis. Am J Hum Genet 1993;52:1102-10.

21 International Human Genome Sequence Consortium. Initial sequence and analysis of the human genome. Nature 2001;409:860-921.

22 Potter GB, Beaudoin GM, DeRenzo CL, Zarach JM, Chen SH, Thompson CC. The hairless gene mutated in congenital hair loss disorders encodes a novel nuclear receptor corepressor. Genes Dev 2001;15:2687-701.

23 Miller J, Diabali K, Chen T, Liu Y, loffreda M, Lyle S, Christiano AM, Holick M, Cotsarelis $G$. Atrichia caused by mutations in the vitamin $D$ receptor gene is a phenocopy of generalized atrichia caused by mutations in the hairless gene. $J$ Invest Dermatol 2001;117:612-17. 